\title{
ARTICLE
}

\section{An experimental investigation for atmospheric effects on Cs chemisorption onto stainless steel}

\author{
Kunihisa Nakajima*, Eriko Suzuki, Naoya Miyahara and Masahiko Osaka \\ Japan Atomic Energy Agency, 2-4 Shirakata, Tokai-mura, Naka-gun, Ibaraki-ken, 319-1195, Japan
}

\begin{abstract}
Effects of atmospheres on the Cs chemisorption onto stainless steel (SS) were experimentally investigated. Basic Cs chemisorption test onto a type-316 SS containing minor components Si and Mo using CsOH as a simulant for $\mathrm{Cs}$ were conducted at $1073 \mathrm{~K}$. A larger weight gain after the test was observed under Ar-5 \% $\mathrm{H}_{2} \mathrm{O}-5 \% \mathrm{H}_{2}$ than under Ar-5 \% $\mathrm{H}_{2}$. Cs-Si-O and Cs-Mo-O were observed as the chemisorbed compounds under Ar-5 \% $\mathrm{H}_{2} \mathrm{O}-5 \% \mathrm{H}_{2}$, while a smaller or no amount of these compounds were observed under Ar-5 \% $\mathrm{H}_{2}$. Of note is an incongruent $\mathrm{Cs}$ vaporization loss from the surface Cs-Si-O compounds under Ar-5 \% $\mathrm{H}_{2}$. These results suggested that $\mathrm{Cs}$ amount in the vapor phase and change of $\mathrm{H}_{2} \mathrm{O}-$ to- $\mathrm{H}_{2}$ ratio should be taken into consideration for an estimation of Cs retention in LWR severe accidents.
\end{abstract}

Keywords: Cesium; chemisorption; stainless steel; Cs-Si-O; Cs-Mo-O; atmosphere; revaporization

\section{Introduction}

Chemical reactions between cesium (Cs) vapor/aerosol and stainless steel (SS) surface are known to occur under a light water reactor (LWR) severe accident (SA) [1-3]. These phenomena, known as the chemisorption, preferentially take place at a surface of LWR SS structural material at a relatively high temperature, i.e. more than $1000 \mathrm{~K}$ which corresponds to the inner structures of the reactor pressure vessel under SA. As the chemisorption can cause a considerable amount of Cs retention, we have conducted a basic research on the Cs chemisorption with a focus on the chemical properties of the Cs chemisorbed materials. In our previous studies [2,3], it has been found that the main Cs vapor species - Cs hydroxide $(\mathrm{CsOH})$ reacts with minor component elements of silicon (Si) and molybdenum (Mo, in the case of Mo-contained type-316 $\mathrm{SS})$ in the $\mathrm{SS}$, and $\mathrm{CsFeSiO}_{4}(\mathrm{Cs}-\mathrm{Si}-\mathrm{O})$ or $\mathrm{Cs}_{2} \mathrm{MoO}_{4}$ (Cs-Mo-O) are formed respectively from above reactions. Although such chemical phenomena are greatly affected not only by the temperature but also by the atmosphere, atmospheric effects have hardly been investigated in detail so far. In this study, therefore, we have experimentally investigated an effect of the steam $\left(\mathrm{H}_{2} \mathrm{O}\right)$ to hydrogen $\left(\mathrm{H}_{2}\right)$ ratio on the $\mathrm{Cs}$ chemisorption behaviors. Results were considered in terms of the chemical properties of the Cs chemisorbed compounds, namely Cs-Si-O and Cs-Mo-O.

\section{Experimental}

An experimental test for Cs Chemical REaction with

*Corresponding author. Email: kunihisa.nakajima@jaea.go.jp stainless STeel for ATMospheric dependence (CREST-ATM) has been conducted by using a Cs chemisorption test setup (Figure 1) under an experimental condition shown in Table 1.

Two types of atmospheres with and without $\mathrm{H}_{2} \mathrm{O}$ were flowed through the furnace. Vaporized $\mathrm{CsOH} \cdot \mathrm{H}_{2} \mathrm{O}$ at $1273 \mathrm{~K}$ was carried by flowing $\mathrm{Ar}-5 \% \mathrm{H}_{2} \mathrm{O}-5 \% \mathrm{H}_{2}$ or Ar-5 $\% \mathrm{H}_{2}$ to the upper part, where the type-316 SS

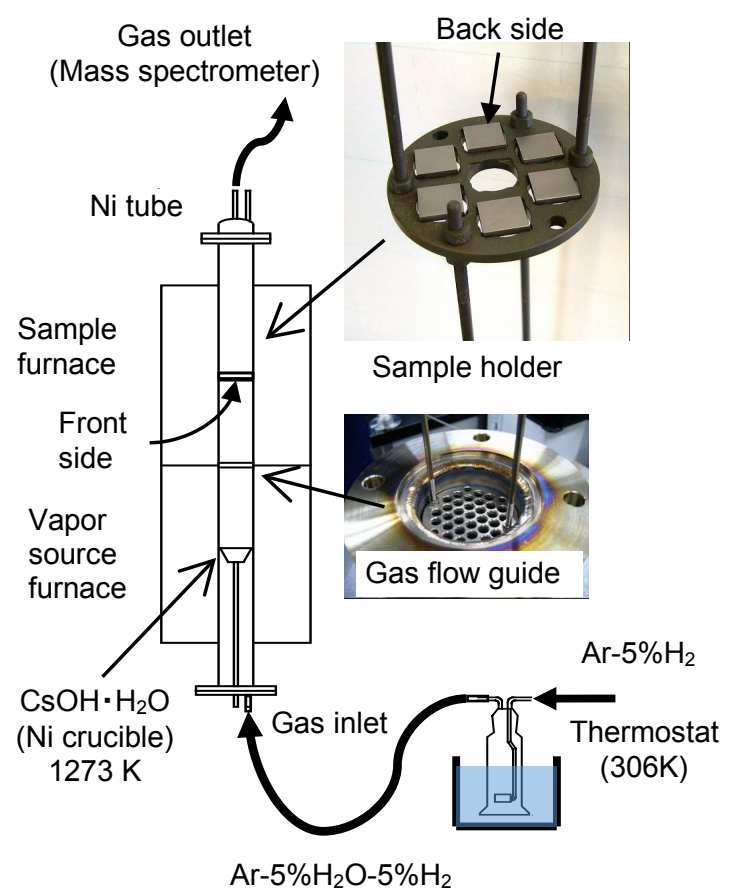

Figure 1. Experimental setup for Cs chemisorption test. 
Table 1. Experimental condition for the Cs chemisorption tests.

\begin{tabular}{|l|l|}
\hline Sample & $\begin{array}{l}\text { Type-316 stainless steel } \\
10 \mathrm{~mm} \times 10 \mathrm{~mm} \text { with } 2-5 \mathrm{~mm} \\
\text { thickness }\end{array}$ \\
\hline Si content & $0.2,1.0,4.9 \mathrm{wt} \%$ \\
\hline Mo content & $2.5 \mathrm{wt} . \%$ \\
\hline Cs vapor source & $\mathrm{CsOH} \cdot \mathrm{H}_{2} \mathrm{O}(\sim 0.5 \mathrm{~g})$ \\
\hline $\begin{array}{l}\text { Heating temperature } \\
\text { (time) }\end{array}$ & $1073 \mathrm{~K}($ holding $3 \mathrm{~h})$ \\
\hline Gas flow rate & $200 \mathrm{~cm}^{3} / \mathrm{min}$. \\
\hline Gas compositions & $\begin{array}{l}\mathrm{Ar}-5 \% \mathrm{H}_{2} \mathrm{O}-5 \% \mathrm{H}_{2} \\
\mathrm{Ar}-5 \% \mathrm{H}_{2}\end{array}$ \\
\hline
\end{tabular}

samples were settled and a Cs chemisorption reaction took place at $1073 \mathrm{~K}$. This chemisorption temperature was chosen based on our previous studies as the considerable Cs chemisorption occurred [2,3]. The reason for selection of type-316 SS is that it contains Mo and $\mathrm{Si}$ as minor components. In addition, amounts of $\mathrm{Si}$ was adjusted from 0.2 to 4.9 wt.\%. It makes a simultaneous investigation of effects of $\mathrm{Si}$ and $\mathrm{Mo}$ on the chemisorbed compounds possible. A calculation by using equilibrium $\mathrm{CsOH}$ vapor pressure based on the experimental condition has shown that $\mathrm{CsOH}$ vaporized completely in less than $30 \mathrm{~min}$. So the subsequent heating up to 3 hours has been carried out without any $\mathrm{CsOH}$ in the vapor phase (hereafter, this heating without $\mathrm{CsOH}$ vapor is called the revaporization heating phase). This revaporization heating phase was intended so as to induce a revaporization of once chemisorbed Cs to occur. A notable feature of this CREST-ATM is variable $\mathrm{Si}$ content in the SS samples. As it has been figured out that the main $\mathrm{Cs}$ chemisorbed compounds was $\mathrm{Cs}-\mathrm{Si}-\mathrm{O}, \mathrm{Si}$ has been considered as one of the major controlling elements for Cs chemisorbed amounts. A remark has to be made on the highest $\mathrm{Si}$ amount of $4.9 \mathrm{wt} . \%$, which is expected to make Si effects more clear.

The weight gains of the SS samples after the Cs chemisorption tests were obtained for the investigation of atmospheric effects. Microstructure observation and identification of Cs chemisorbed compounds have been performed by the analyses with scanning electron microscopy/energy dispersive X-ray (SEM/EDX) spectroscopy and X-ray diffraction (XRD) analysis on the SS samples after the chemisorption tests.

\section{Results and discussion}

Figure 2 shows the weight gains of the SS samples after the chemisorption tests for each atmosphere plotted versus Si contents. It is clearly seen that the weight gains are larger under Ar-5 \% $\mathrm{H}_{2} \mathrm{O}-5 \% \mathrm{H}_{2}$ than those under Ar-5 $\% \mathrm{H}_{2}$. Increasing tendency of the weight gains with increase of the Si contents is another notable result.

Figure 3 shows elemental distributions on the Cs chemisorbed SS surfaces by the SEM/EDX analysis. Although it is unclear by the present SEM/EDX images, congruent distribution of $\mathrm{Cs}$ and $\mathrm{Si}$ could occur, considering our previous study, which indicates presence of Cs-Si-O compounds [2,3], and the Si content

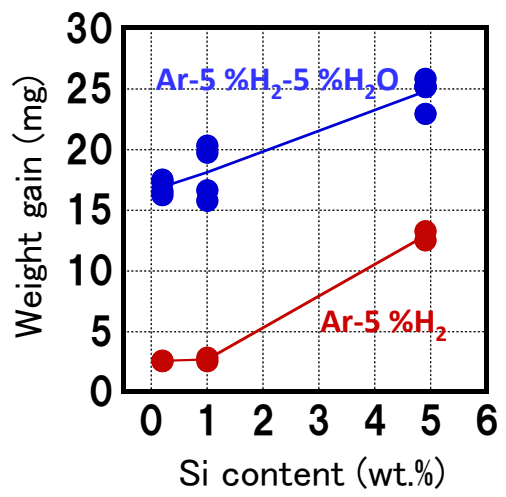

Figure 2. Weight gains of the SS samples after Cs chemisorption tests.

dependence of the weight gains as shown in Figure 2. It is noted that a congruent distribution of $\mathrm{Cs}$ and $\mathrm{Mo}$, which means the formation of Cs-Mo-O compounds based on our previous result [2], was observed only in the $\mathrm{Ar}-5 \% \mathrm{H}_{2} \mathrm{O}-5 \% \mathrm{H}_{2}$ atmosphere.
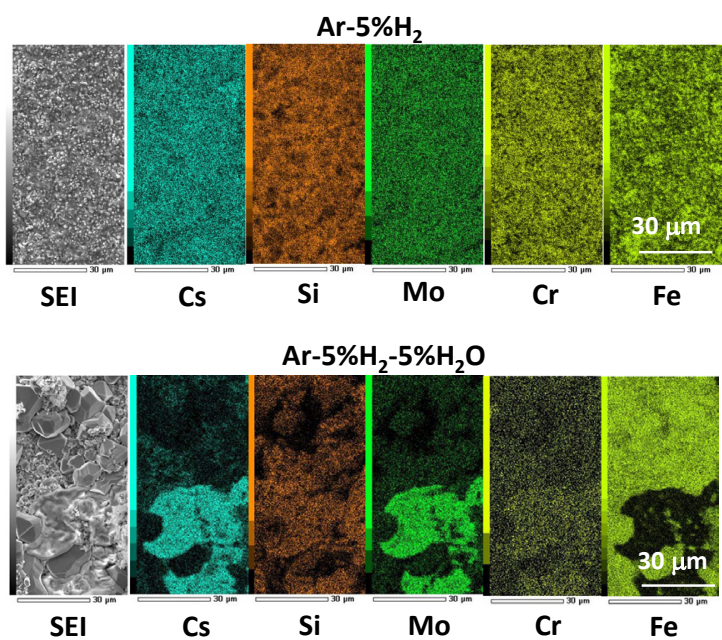

Figure 3. Elemental distribution on the surface of SS samples after Cs chemisorption tests.

Cross sectional observation of the elemental distribution is shown in Figure 4. A clear difference is seen between the remaining $\mathrm{Cs}-\mathrm{Si}-\mathrm{O}$ compounds in Ar-5 \% $\mathrm{H}_{2} \mathrm{O}-5 \% \mathrm{H}_{2}$ and those in $\mathrm{Ar}-5 \% \mathrm{H}_{2}$. Namely, no surface $\mathrm{Cs}$ is remained in Ar-5 $\% \mathrm{H}_{2}$, while some still exists in the depth region of the oxide layer near the metal matrix after the revaporization heating phase.

It is considered that the surface Cs-Si-O compounds were decomposed to release Cs by some interaction with $\mathrm{H}_{2}$ in $\mathrm{Ar}-5 \% \mathrm{H}_{2}$, considering that $\mathrm{Si}$ was still remained on the surface. This incongruent vaporization of Cs from the Cs-Si-O compounds by the revaporization heating phase is discussed in detail in another paper [4]. Another notable result in this paper [4] is faster vaporization loss of $\mathrm{CsFeSiO}_{4}$ under $\mathrm{Ar}-5 \% \mathrm{H}_{2}$ than that under Ar-5 \% $\mathrm{H}_{2} \mathrm{O}-5 \% \mathrm{H}_{2}$.

The difference of the weight gain in Figure 2 is discussed below based on the above-mentioned results. Under $\mathrm{Ar}-5 \% \mathrm{H}_{2}$ there are not any Cs-Mo-O compounds, 

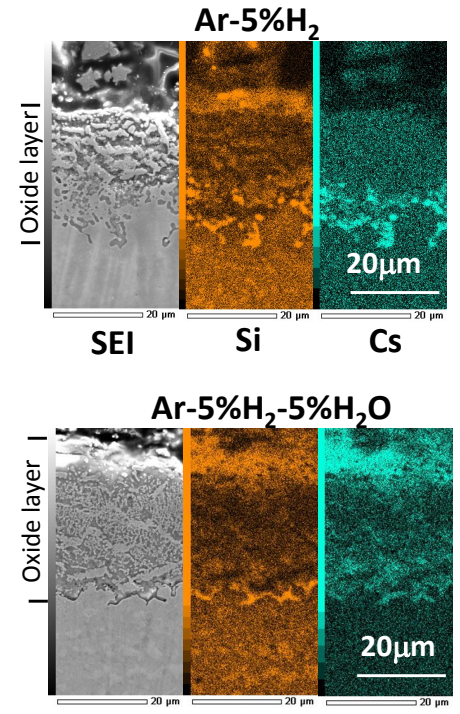

Figure 4. Elemental distribution of the cross section of SS samples after Cs chemisorption tests.

and the smaller weight gain of SS would correspond to the smaller remaining of $\mathrm{Cs}-\mathrm{Si}-\mathrm{O}$ chemisorbed compounds, which exists only inside the SS sample. This has been brought by the faster revaporization loss, or probably decomposition to release only Cs from the surface Cs-Si-O compounds, which is present before the revaporization heating phase. On the other hand, existence of not only the Cs-Mo-O compounds but also Cs-Si-O compounds with less revaporization have caused the larger weight gains under $\mathrm{Ar}-5 \% \mathrm{H}_{2} \mathrm{O}-5 \% \mathrm{H}_{2}$. As another cause of the larger weight gain, sample oxidation can be also considered. However, Figure 4 shows almost the same thickness of the oxide layers and mass number of oxygen is much lower than that of cesium. Therefore, sample oxidation could little contribute to the weight difference.

\section{Conclusion}

An experimental investigation test CREST-ATM for the effects of atmosphere on the Cs chemisorption has been conducted. It was observed that the weight gain after Cs chemisorption test was larger under Ar-5 $\% \mathrm{H}_{2} \mathrm{O}-5 \% \mathrm{H}_{2}$ than that in $\mathrm{Ar}-5 \% \mathrm{H}_{2}$. This was considered to be brought by the different vaporization behaviors of Cs-Si-O and Cs-Mo-O between under Ar- $5 \% \mathrm{H}_{2} \mathrm{O}-5 \% \mathrm{H}_{2}$ and $\mathrm{Ar}-5 \% \mathrm{H}_{2}$ atmospheres.

The present results should be taken into consideration for an estimation of Cs retention amount in the LWR experienced SA, since Cs amounts and $\mathrm{H}_{2} \mathrm{O}-$ to- $\mathrm{H}_{2}$ ratios in the vapor phase are continuously changed along with the SA progression.

\section{Acknowledgements}

The authors wish to thank members of Cs-chemistry team for an invaluable discussion on this study. Mr. K. Ebata and Mr. J. Takada are greatly appreciated for their helpful support to the experiment.

\section{References}

[1] V.F. Baston, K.J. Hofstetter, G.M. Bain and R.M. Elrick, A comparison of TMI-2 and laboratories results for cesium activity retained on reactor material surface, Proc. American Nuclear Society Winter Meeting, Nov. 10-14, 1985, San Francisco, CA, USA, (1985), pp. 223-225.

[2] F.G. Di Lemma, K. Nakajima, S. Yamashita and M. Osaka, Experimental investigation of the influence of Mo contained in stainless steel on Cs chemisorption behavior, Nucl. Eng. Des. 305 (2016), pp. 411-420.

[3] F.G. Di Lemma, K. Nakajima, S. Yamashita and M. Osaka, Surface analyses of cesium hydroxide chemisorbed onto type 304 stainless steel, J. Nucl. Mater. 484 (2017), pp. 174-182.

[4] E. Suzuki, K. Nakajima, M. Osaka, Effect of atmosphere on the vaporization behavior of CsFeSiO4, Prog. Nucl. Sci. Technol. 5 (2018), pp.165-167. 